\title{
PRODUÇÃO DE MUDAS DE TOMATE CEREJA COM USO DE POLÍMERO E DIFERENTES REGIMES DE REPOSIÇÃO HÍDRICA
}

\author{
Luis Eduardo Vieira Pinto ${ }^{1}$, Ana Carolina Geraldo de Maria ${ }^{2}$, Fernando Bernardo Martins ${ }^{1}$, Valter \\ Alves Pradela ${ }^{2}$ \\ ${ }^{1}$ Universidade do Oeste Paulista - UNOESTE, Programa de Pós-Graduação em Agronomia, Presidente Prudente, SP. \\ ${ }^{2}$ Faculdade de Tecnologia de Presidente Prudente - FATEC, Curso de Agronegócio. E-mail: levp@unoeste.br
}

\section{RESUMO}

A cadeia produtiva do tomate é uma das mais importantes da indústria alimentícia brasileira, dentre as cultivares de tomate, tem sido crescente a demanda pela variedade cereja, devido à grande aceitação pelos consumidores. O objetivo do trabalho foi avaliar o desenvolvimento das mudas de tomate cereja em função de diferentes regimes de reposição hídrica através da utilização de polímeros hidroabsorventes (Hidrogel). Utilizou-se no experimento um delineamento inteiramente casualizado, adotando o esquema fatorial $(5 \times 5)$, sendo 5 doses de polímero (1 grama/litro de substrato; 2 gramas/litro de substrato; 3 gramas/litro de substrato; 4 gramas/litro de substrato; testemunha - sem adição de hidrogel), com 5 regimes de reposição hídrica (diariamente; dia sim e dia não; dia sim e dois dias não; dia sim e três dias não; dia sim e quatro dias não). $\mathrm{O}$ uso de 2 gramas de hidrogel proporcionou o melhor desenvolvimento da parte aérea das mudas dentro de cada regime hídrico.

Palavras-chave: Agronegócio. Água. Substrato. Agricultura Familiar. Hidrogel.

\section{PRODUCTION OF CHERRY TOMATO CHIPS WITH POLYMER USE AND DIFFERENT WATER RESOURCE REGIMES}

\begin{abstract}
The tomato production chain is one of the most important in the Brazilian food industry, among the tomato cultivars, the demand for the cherry variety has been increasing due to the great acceptance by the consumers. The objective of this work was to evaluate the development of cherry tomatoes in response to different water replenishment regimes through the use of hydroabsorbent polymers (Hydrogel). A completely randomized design was used, using the factorial scheme $(5 \times 5)$, with 5 doses of polymer (1 gram / liter of substrate, 2 grams / liter of substrate, 3 grams / liter of substrate, 4 grams / liter of substrate, control - without addition of hydrogel), with 5 water replenishment regimes (daily, day and day no, day yes and two days no, day yes and three days no, day yes and four days no). The use of 2 grams of hydrogel provided the best development of the aerial part of the seedlings within each water regime.
\end{abstract}

Keywords: Agribusiness. Water. Substrate. Family farming. Hydrogel.

\section{INTRODUÇÃO}

A cultura do tomateiro (Lycopersicon esculentum) é de grande importância para a dieta alimentar do brasileiro. Essa hortaliça produz frutos, que é um alimento composto de açúcares, sólidos insolúveis em álcool, ácidos orgânicos, minerais, vitaminas $A, B 1, B 2, B 3, B 6, C$, E, ácido fólico, biotina, além de outros compostos (SILVA e GIORDANO, 2000). O grupo cereja destaca-se pelo seu alto valor comercial e ampla aceitação pelo consumidor. Esse grupo apresenta muitas variedades regionais com boa tolerância a doenças foliares e pragas (SOUZA, 2003). 
É importante ressaltar que o tomate pertencente à espécie Lycopersicon pimpinellifolium se destaca pela sua rusticidade, sendo considerada por muitos como do grupo cereja, devido ao tamanho dos seus frutos (MINAMI e HAAG, 1989). LORENZI e MATOS (2002) admitem que o Lycopersicon pimpinellifolium possui propriedades semelhantes ao tomate comum, possuindo polpa com atividades antifúngicas, devido à presença de tomatina, além de atividades antihistamínica, anti-inflamatória e inibidora da absorção de colesterol.

O sucesso do cultivo de hortaliças depende em grande parte da utilização de mudas de alta qualidade, o que torna o cultivo de hortaliças mais competitivo, com o aumento de produtividade e diminuição dos riscos de produção (MINAMI, 1995). A produção de mudas de hortaliças sob cultivo protegido tem apresentado um crescimento expressivo, em decorrência das vantagens em relação ao sistema tradicional.

A base da horticultura moderna é a produção de mudas de alta qualidade e uma muda bem formada dará origem a uma planta com alto potencial produtivo. Para produtores de mudas, ocorre a tendência de se comercializarem mudas mais novas, para reduzir o tempo destas no viveiro de produção. Já, os produtores que irão cultivar estas mudas, preferem-nas mais desenvolvidas. Provavelmente, essa preferência está relacionada com a facilidade de transplante, pois estas apresentam um sistema radicular compacto, estruturado com um torrão que não se quebra no momento da retirada das bandejas (SEABRA JÚNIOR et al., 2004).

$\mathrm{O}$ uso de polímeros hidrorretentores e condicionantes de solo pode ser uma alternativa para minimizar problemas vinculados à deficiência hídrica. Estes polímeros são produtos naturais (derivados do amido) ou sintéticos que são reconhecidos pela capacidade de absorção e retenção da água gravitacional na rizosfera (LECIEJEWSKI, 2009), assim como suas propriedades de melhoria nas características físicas dos solos (VALE et al., 2006).

No Brasil, os estudos com hidrogéis ganharam destaque com os trabalhos desenvolvidos por Balena (1998) e Azevedo (2000). Segundo Azevedo et al. (2002), os polímeros sofrem degradação no solo e, não existe nenhum problema relacionado à toxicidade residual. Alguns tipos de polímeros são utilizados nas mudas de espécies de grande porte (plantio de Eucalipto). As tecnologias evoluíram muito, e o Brasil é referência mundial em eucalipto (EMBRAPA, 2004).

Novas técnicas e tecnologias são geradas e investigadas, como, por exemplo, os estudos envolvendo o plantio com polímeros sintéticos, com o objetivo de reduzir as irrigações. No Paraná especificamente, a utilização dos hidrogéis está mais focada nos povoamentos florestais de eucalipto e pinus (VALE et al., 2006). Para a agricultura familiar, o estudo de alternativas de racionalização da água utilizada na irrigação de algumas olerícolas de ciclo longo (e que pode ser estendido às frutíferas) ou a não utilização de irrigação sem prejudicar o desenvolvimento da cultura são de fundamental interesse de pequenos agricultores uma vez que a água da chuva poderá ser suficiente, em alguns casos de culturas de ciclo curto, como a maioria das olerículas, gerando benefícios econômicos e ambientais.

O objetivo do trabalho foi avaliar o desenvolvimento das mudas de tomate cereja em função de diferentes regimes de reposição hídrica através da utilização de polímeros hidroabsorventes (Hidrogel).

\section{METODOLOGIA}

O experimento foi conduzido na área experimental da Fatec (Faculdade de Tecnologia de Presidente Prudente - SP). Utilizou-se um delineamento inteiramente casualizado, adotando o esquema fatorial $(5 \times 5)$, sendo 5 doses de polímero hidrogel ( 1 grama por litro de substrato; 2 gramas por litro de substrato; 3 gramas por litro de substrato; 4 gramas por litro de substrato; testemunha - sem adição de hidrogel), com 5 regimes de reposição hídrica (diariamente; dia sim e dia não; dia sim e dois dias não; dia sim e três dias não; dia sim e quatro dias não) e 60 repetições. 
Para que pudesse ocorrer uma melhor ação do polímero hidrogel junto ao substrato, foi realizado inicialmente a mistura de cada dose do polímero em $150 \mathrm{ml}$ de água morna, objetivando a hidratação do mesmo conforme recomendação do fabricante do produto. A semeadura do tomate foi realizada em bandejas plásticas de mudas de 200 células, no período de março de 2017, utilizando três sementes por célula e realizando o desbaste após a germinação. Realizado o desbaste, as plantas foram submetidas a irrigação no volume de 4 mililitros por muda, divido em 2 períodos distintos do dia (manhã e tarde) conforme a variação das taxas de irrigação, aplicados com o auxílio de uma seringa.

Vinte dias após o plantio as mudas foram retiradas das bandejas para a realização da operação de lavagem do sistema radicular, visando a retirada dos agregados de substrato, após a lavagem as mudas foram postas a secar sob papel do tipo Kraft à sombra.

O comprimento da raiz e parte aérea foi realizado utilizando uma fita métrica aprovada e homologada pelo Inmetro (Instituto Nacional de Metrologia, Qualidade e Tecnologia). Para a determinação da massa seca da raiz e parte aérea foi utilizado uma estufa de circulação de ar quente no qual as mudas ficaram por um período de 72 horas a uma temperatura na faixa de 65 75 ㅇ. .

Os dados obtidos foram submetidos à análise de variância e as médias submetidas a análise de regressão a $5 \%$ de probabilidade. A avaliação estatística do experimento foi realizada em programa computacional SISVAR Sistema para Análise de Variância (FERREIRA, 2000) e os gráficos foram gerados através do programa Excel 2013.

\section{RESULTADOS}

A partir dos resultados obtidos nas figuras 01,02 e 03 nota-se que houve uma resposta positiva de desenvolvimento das plantas quando utilizado a dose de 2 gramas de hidrogel por litro de substrato em associação com a irrigação realizada diariamente. Com relação à produção de mudas, a necessidade hídrica, em sua fase de formação e desenvolvimento, é de fundamental importância. A falta de água pode levar ao estresse hídrico e diminuir a absorção de nutrientes pelas plantas. Já o excesso pode favorecer a lixiviação dos nutrientes e ainda proporcionar microclima favorável ao desenvolvimento de doenças, além das questões socioambientais relativas à economia de água e acúmulo de lixiviados no solo (LOPES, 2005).

Figura 01. Comprimento da parte aérea das mudas de tomate cereja em função dos diferentes tratamentos.
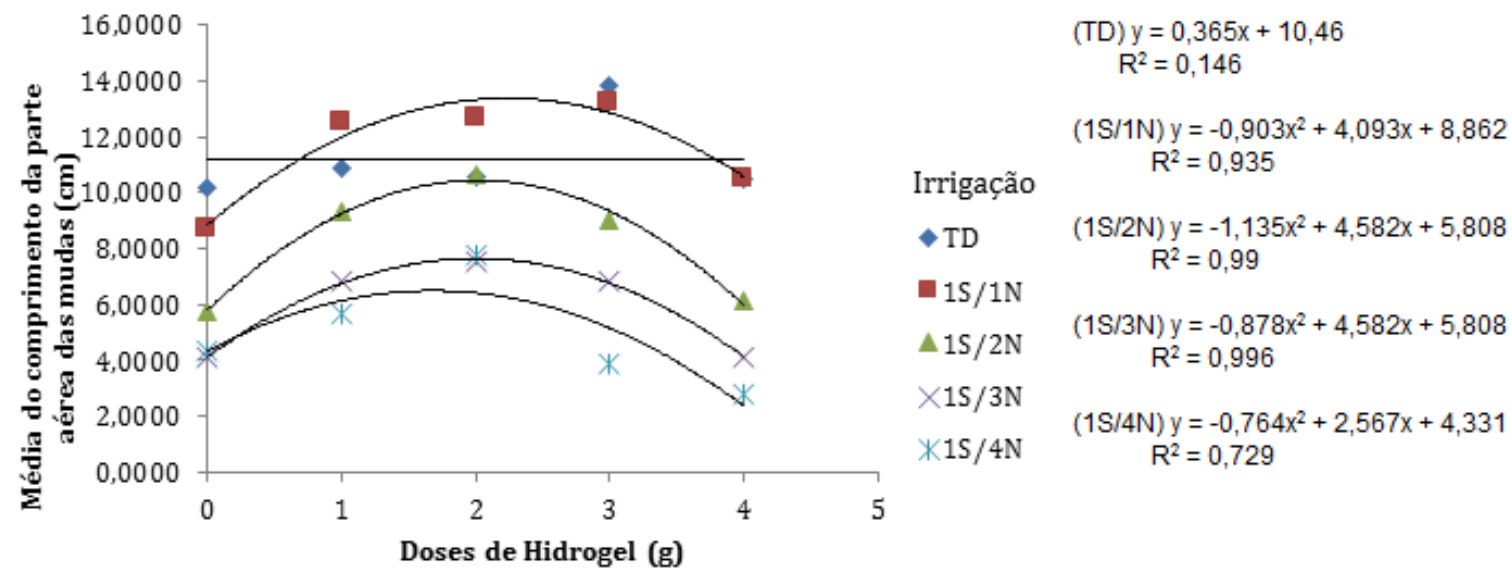
Figura 02. Comprimento da raiz das mudas de tomate cereja em função dos diferentes tratamentos.

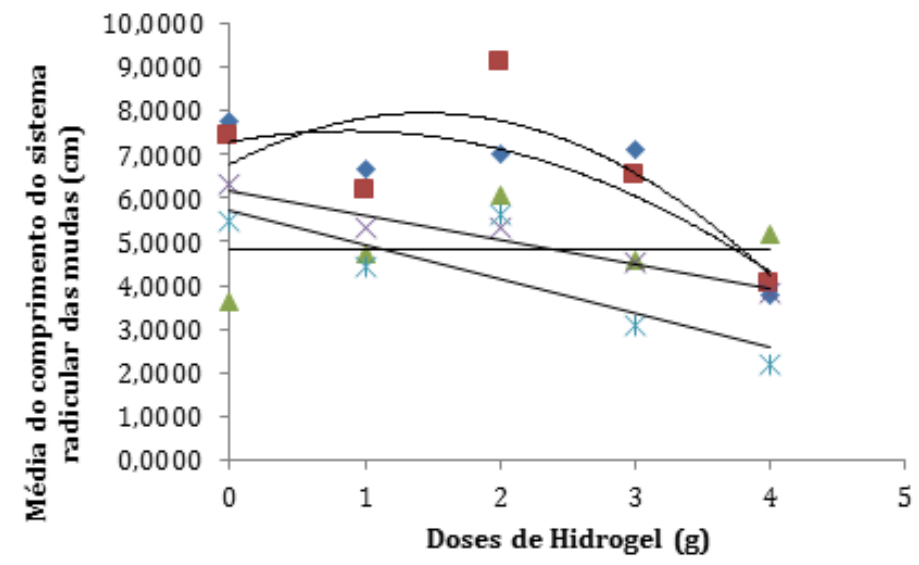

$$
\begin{array}{crl} 
& \text { (TD) } y=-0,332 x^{2}+0,583 X+7,285 \\
R^{2}=0,748 & \\
\text { Irrigação } & (1 S / 1 N) y=-0,567 x^{2}+1,636 x+6,774 \\
\text { TD } & R^{2}=0,628 \\
\square 1 S / 1 N & (1 S / 2 N) y=-0,275 x^{2}+1,385 x+3,72 \\
\Delta 1 S / 2 N & R^{2}=0,615 \\
\times 1 S / 3 N & (1 S / 3 N) y=-0,565 x+6,19 \\
* 1 S / 4 N & R^{2}=0,945 \\
& (1 S / 4 N) y=-0,785 x+5,73 x \\
& R^{2}=0,701
\end{array}
$$

Figura 03. Massa seca (raiz e parte) aérea das mudas de tomate cereja em função dos diferentes tratamentos.

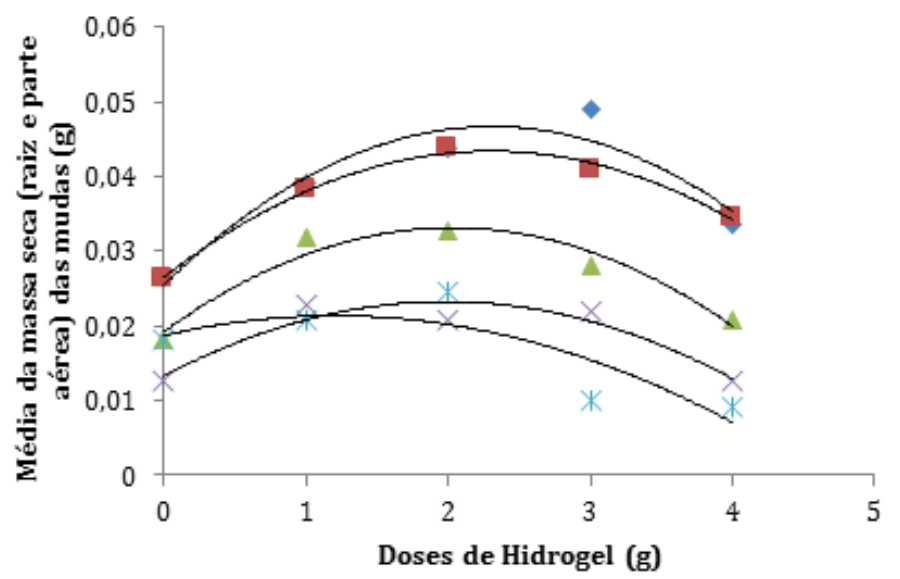

$$
\begin{array}{crl} 
& \text { (TD) y }=-0,004 x^{2}+0,018 x+0,025 \\
R^{2}= & 0,903 \\
\text { Irrigação } & (1 S / 1 N) y=-0,003 x^{2}+0,014 x+0,026 \\
\text { TD } & R^{2}=0,992 \\
\square 1 S / 1 N & (1 S / 2 N) y=-0,003 x^{2}+0,013 x+0,019 \\
\triangle 1 S / 2 N & R^{2}=0,939 \\
\times 1 S / 3 N & (1 S / 3 N) y=-0,002 x^{2}+0,01 x+0,013 \\
\times 1 S / 4 N & R^{2}=0,891 \\
& (1 S / 4 N) y=-0,001 x^{2}+0,004 x+0,018 \\
& R^{2}=0,711
\end{array}
$$

\section{DISCUSSÃO}

No sistema produtivo das hortaliças uma das partes mais importantes, é a produção das mudas, pois consequentemente, influencia na produção final das plantas. Os produtores têm buscado novas técnicas para a produção de mudas, buscando garantir uma população uniforme e sem falhas.

A crescente pressão para a produção de mudas com alta qualidade exige um entendimento melhor da fisiologia do crescimento e das relações hídricas das plantas em fase inicial de desenvolvimento. Um aspecto de particular importância, nesse sentido, diz respeito ao conhecimento das respostas fisiológicas das mudas à diminuição da água disponível no "substrato", ou seja, aumento do déficit hídrico.

Observa-se que independe das variáveis avaliadas no experimento e das doses utilizadas do polímero hidrogel, os resultados mais significativos estão associados com a utilização diária de irrigação ou no máximo com o intervalo de um dia. Paiva e Oliveira (2006) asseguram que a água tem propriedades que lhe permite atuar como um solvente e ser prontamente transportada ao longo do corpo da planta. Tais propriedades derivam primariamente da estrutura polar da molécula de água, a água tanto faz parte de moléculas presentes no protoplasma celular como compõe água de hidratação e soluções, dissolvendo íons e pequenas substâncias orgânicas. Segundo Costa (2001), as principais funções da água nas plantas podem ser analisadas na estrutura, no crescimento, no transporte, no metabolismo e outras. O oxigênio e o dióxido de 
carbono necessários à respiração e à fotossíntese encontram-se dissolvidos na água, dependendo ambos os processos da solubilidade daqueles gases na água.

Para as variáveis crescimento da parte aérea e massa seca das mudas, percebe-se que independente da taxa variada de irrigação, a dose equivalente a 2 gramas do polímero hidrogel misturada ao substrato, promoveu ganhos significativos de tamanho e massa nas mudas avaliadas no experimento. Doses maiores de polímero não refletiram em mudas melhores, segundo Beltrão et al. (2001) o estresse hídrico, tanto por deficiência como excesso reduz a altura das plantas, a fitomassa total e a relação raiz/parte aérea, fotossíntese da planta, bem como o processo respiratório oxidativo, além de alterações no metabolismo da planta, como redução da atividade da invertase, enzima chave no metabolismo dos açúcares, transformando a sacarose em glicose e frutose, e incremento da atividade da enzima T-amilase, especialmente com o excesso de água no solo, e deficiência de oxigênio. Pinto (2010) estudando o uso de polímeros na cultura de canavieira concluiu que o uso do hidrogel promoveu uma maior produção de biomassa de canade-açúcar, consequentemente produzindo um maior potencial de bioenergia do sistema e até mesmo influenciando na qualidade da planta em função de maior acúmulo de sólidos solúveis.

O desenvolvimento de qualquer parte da planta está comprovadamente relacionado à disponibilidade de água e nutrientes (LOPES, 2004). A falta de água e nutrientes afeta diretamente o crescimento em altura e em diâmetro, reduzindo a expansão celular e a formação da parede celular, influenciando negativamente a produção de reguladores de crescimento (SASSE et al., 1996). Tal implicação foi constatada na utilização de concentrações adequadas do hidroretentor, proporcionando incremento de massa seca da parte aérea.

Marques e Bastos (2010) em estudo com doses de hidrogel em cultura de pimentão verificou que a massa seca apresentou diferenças significativas entre os tratamentos de doses de hidrogel, porém observou que não houve interferência no sistema radicular de muda de pimentão. Resultados estes que são similares aos obtidos no experimento quando avaliando o comprimento das raízes, entende-se que o sistema radicular das mudas foi menor nos tratamentos com o uso do polímero. Altas concentrações de hidrogel já foram relacionadas com menor formação de raiz em pesquisas realizadas por HAFLE et al. (2008) sobre a produção de mudas do maracujazeiro-doce utilizando hidrogel e por CRUZ et al. (2008) no desenvolvimento de porta-enxerto de tangerina.

\section{CONCLUSÃO}

O uso de 2 gramas de hidrogel proporcionou o melhor desenvolvimento da parte aérea das mudas dentro de cada regime hídrico.

O uso do polímero pode auxiliar o desenvolvimento das mudas de tomate cereja, quando as mesmas forem submetidas a períodos curtos de estresse hídrico.

\section{REFERÊNCIAS BIBLIOGRÁFICAS}

AZEVEDO, T. L. F. Avaliação da eficiência do polímero agrícola de poliacrilamida no fornecimento de água para o cafeeiro (Coffea arabica L) cv. Tupi. 2000. 38 p. Dissertação (Mestrado). Universidade Estadual de Maringá, Maringá, 2000.

AZEVEDO, T. L. F.; BERTONHA, A.; GONÇALVES, A. C. A. Uso de hidrogel na agricultura. Revista do Programa de Ciências Agro-Ambientais. v.1, n.1, p.23-32, 2002. 
BALENA, S. P. Efeito de polímeros hidroretentores nas propriedades físicas e hidráulicas de dois meios porosos. 1998. 57 p. Dissertação (Mestrado em Ciência do Solo) - Universidade Federal do Paraná, Curitiba.

BELTRÃO, N. E. de M.; SILVA, L. C.; VASCONCELOS, O. L. AZEVEDO, D. M. P. de VIEIRA, D. J. Fitologia. In: AZEVEDO, D. M. P. de LIMA, E. F. (Ed). O agronegócio da mamona no Brasil. Brasília, DF: Embrapa Informação Tecnológica, 2001. p. 37-61.

COSTA, A. R. Texto academico: As Relações Hídricas Das Plantas Vasculares. Portugal. Editora da Universidade de Évora, 2001. 75 p.

CRUZ, M.C.M.; HAFLER, O.M.; RAMOS, J.D.; RAMOS, P.S. Desenvolvimento do porta-enxerto de tangerineira 'cleópatra'. Revista Brasileira de Fruticultura, Jaboticabal - SP, v. 30, n. 2, p. 471-475, Junho 2008.

EMBRAPA. EMPRESA BRASILEIRA DE PESQUISA AGROPECUÁRIA. Florestas - Brasil é referência mundial em eucalipto. 2004, disponível em , acesso em 02/12/2010.

FERREIRA, D.F. Análises estatísticas por meio do Sisvar para Windows versão 4.0. In... REUNIÃO ANUAL DA REGIÃO BRASILEIRA DA SOCIEDADE INTERNACIONAL DE BIOMETRIA, 45, 2000. Anais... São Carlos, SP: SIB, p. 255-258, 2000.

HAFLER, O.M.; CRUZ, M.C.M.; RAMOS, J.D.; RAMOS, P.S.; SANTOS, V.A. Produção de mudas de maracujazeiro-doce através da estaquia utilizando polímero hidrorretentor. Revista Brasileira de Ciências Agrárias, v. 3, n. 3, p. 232-236, 2008. https://doi.org/10.5039/agraria.v3i3a292

LECIEJEWSKI, P. The effect of hydrogel additives on the water retention curve of sandy soil from forest nursery in Julinek. Journal Water Land Development, v.13a, p.239- 247, 2009.

https://doi.org/10.2478/v10025-010-0031-8

LOPES, J.L.W. Efeitos na irrigação na sobrevivência, transpiração e no teor relativo de água na folha em mudas de Eucalyptus grandis em diferentes substratos. Scientia Forestalis, Piracicaba, n.68, p.97-106, 2005.

LOPES,J.L.W. Produção de mudas de Eucalyptusgrandis (Hill ex. Mainden) em diferentes substratos e lâminas de irrigação. Botucatu, UNESO, 2004. 100 p.:il. Dissertação (mestrado em Agronomia) - Universidade Estadual Paulista, 2004.

LORENZI, H.; MATOS, F.J.A. Plantas medicinais no Brasil: nativas e exóticas. Nova Odessa: Instituto Platarum, 2002.

MARQUES, P.A.A.; BASTOS, R.O. Uso de diferentes doses de hidrogel para produção de mudas de pimentão. Pesquisa aplicada e Agrotecnologia, 2010. São Paulo.

MINAMI, K; HAAG, H. P. O tomateiro. 2 ed. Campinas: Fundação Cargill, 1989, 397p.

MINAMI, K. (Ed.) Produção de mudas de alta qualidade em horticultura. São Paulo: T.A Queiroz, $199512 \mathrm{p}$. 
PAIVA, R.; OLIVEIRA, L.M. Fisiologia e Produção Vegetal. Lavras. Ed. UFLA, 2006. 104 p.

PINTO, L. E. V. Energia da biomassa de cana-de-açúcar sob influência de hidrogel e cobertura vegetal em dois sistemas de plantio. 2010. 77 p. Dissertação (Mestrado em Produção Vegetal) Universidade do Oeste Paulista, Presidente Prudente.

SASSE, J.; SANDS, R.; WHITEHEAD, D.; KELLIHER, F.M. Comparative responses of cutting and seddlings of Eucalyptus globulus to water stress.TreePhysiology; v. 16 p.287 - 294, 1996. https://doi.org/10.1093/treephys/16.1-2.287

SEABRA JÚNIOR, S.; GADUM, J.; CARDOSO, I.I. Produção de pepino em função da idade das mudas produzidas em recipientes com diferentes volumes 34 de substrato. Horticultura Brasileira, Brasília, v,22, n.3, p.610-613, jul./set .2004.

SILVA, J. B. C.; GIORDANO, L. B. Tomate para processamento industrial. Brasília: EmbrapaHortaliças, 2000. 168p.

VALE, G. R. F.; CARVALHO, S. P.; PAIVA, L. C. Avaliação da eficiência de polímeros hidroretentores no desenvolvimento do cafeeiro em pós-plantio. Coffe Science, v. 1, n. 1, p. 07- 13, 2006. 